\title{
Bir İnsansız Su Üstü Aracının Dış Bozucu Etkisinde Makine Öğrenmesi ile Hız Kontrolü
}

\author{
Recep Fatih Cantekin ${ }^{1}$, Berna Erol $^{2}$, Seda Karadeniz Kartal $^{3^{*}}$ \\ ${ }^{1}$ Zonguldak Bülent Ecevit Üniversitesi, Mühendislik Fakültesi, Elektrik Elektronik Bölümü, Zonguldak, Türkiye (ORCID: 0000-0002-2130-894X), \\ recep cantekin@hotmail.com \\ ${ }^{2}$ Zonguldak Bülent Ecevit Üniversitesi, Mühendislik Fakültesi, Elektrik Elektronik Bölümü, Zonguldak, Türkiye (ORCID: 0000-0001-7381-9840), \\ erolberna4@gmail.com \\ 3* Zonguldak Bülent Ecevit Üniversitesi, Mühendislik Fakültesi, Elektrik Elektronik Bölümü, Zonguldak, Türkiye (ORCID: 0000-0003-4756-5490), \\ sedakaradeniz@gmail.com
}

(3rd International Congress on Human-Computer Interaction, Optimization and Robotic Applications June 11-13, 2021)

(DOI: 10.31590 /ejosat.952256)

ATIF/REFERENCE: Cantekin, R.F., Erol, B. \& Kartal, S. (2021). Bir İnsansız Su Üstü Aracının Dış Bozucu Etkisinde Makine Öğrenmesi İle Hız Kontrolü. Avrupa Bilim ve Teknoloji Dergisi, (26), 431-437.

\section{Öz}

İnsansız su üstü araçlarının kontrolü, kullanım alanlarının her geçen gün artması nedeniyle önemli bir konu haline gelmiştir. Bu çalışmada bir insansız su üstü aracının (WAM-V USV14) akıntı etkisi altında iticilerine verilmesi gereken uygun girişlerin kontrolü sunulmuştur. İlk olarak WAM-V USV14 için üç serbestlik derecesine sahip matematiksel model elde edilmiştir. İnsansız su üstü aracının doğrusal olmayan matematiksel modeli Newton-Euler yaklaşımı ile elde edilmiştir. İnsansız su üstü araçlarının kontrolü için literatürde yapılan birçok çalışma mevcuttur. Bununla birlikte insansız su üstü araçları için yeni kontrolcü tekniklerinin geliştirilmesi güncel bir konudur. Tasarlanan kontrolcülerin araca etki eden dış bozuculardan etkilenmemesi istenmektedir. İnsansız su üstü aracına etki eden dış bozucular, okyanus akıntısı, dalga, rüzgar vb. olabilir. Dış bozucular aracın konumu, yönünü ve hızını etkiler. Bundan dolayı aracın istenen görevleri yerine getirememesine neden olabilir. Bu çalışmada insansız su üstü aracının kontrolü için makine öğrenmesi yöntemi önerilmiştir. Mevcutta kullanılan klasik kontrol tekniklerine alternatif bir yöntem olarak makine öğrenmesi ile dış bozucuların etkisinde, su üstü aracının hızı kontrol edilmiştir. Aracın hız kontrolünü sağlayan, makine öğrenme algoritması olan destek vektör makinesi için PID kontrolcü ile farklı referans sinyallere karşı aracın iticilerine girdi bilgileri üretilerek veriseti oluşturulmuştur. Su üstü araçları akıntıya maruz kaldıklarında yana kayma ve hücum açıları meydana gelir. Yana kayma ve hücum açıları tanımlanarak araca etki eden akıntının etkisi analiz edilmiştir. Farklı yön ve hızlardan gelen akıntıya karşı aracın hızı, destek vektör makinesi ile başarılı bir şekilde kontrol edilmiştir. Literatürde kullanılan kontrol tekniklerinden farklı olarak SVM'nin su üstü aracının kontrolünde kullanılması bu çalışmanın katkısıdır. Tüm çalışma MATLAB/Simulink ortamında yapılmıştır.

\section{The Velocity Control with Machine Learning under the External Disruption of an Unmanned Sea-Surface Vehicle}

\begin{abstract}
Control of unmanned surface vehicles has become an important issue due to the increase in usage areas day by day. In this study, the control of suitable inputs that should be given to the thrusters of an unmanned surface vehicle (WAM-V USV14) under the current effect is presented. Firstly, a mathematical model with three degrees of freedom is obtained for WAM-V USV14. The nonlinear mathematical model of unmanned sea-surface vehicle (WAM-V USV14) is obatined with Newton-Euler approach.
\end{abstract}

\footnotetext{
* Sorumlu Yazar: Zonguldak Bülent Ecevit Üniversitesi, Mühendislik Fakültesi, Elektrik-Elektronik Mühendisliği Bölümü, Zonguldak, Türkiye, ORCID: 0000-0003-4756-5490, sedakaradeniz@,gmail.com
} 
There are many studies in the literature for the control of unmanned surface vehicles. In addition, the development of new control techniques for unmanned surface vehicles is a current issue. It is desired that the designed controllers are not affected by external disturbances affecting the vehicle. External disturbances affecting the unmanned surface vehicle may be ocean current, wave, wind, etc. External disturbances affect the position, direction and speed of the vehicle. Therefore, it may cause the vehicle to fail to perform the requested tasks. In this study, machine learning method is proposed for the control of unmanned surface vehicle. The surge velocity of the sea- surface vehicle was controlled with machine learning as an alternative to the conventional control techniques currently used. For the support vector machine, which is the machine learning algorithm that provides the velocity control of the vehicle, the data set was created by generating input information for the vehicle's thrusters against different reference signals with PID controller. When surface vehicles are exposed to current, sideslip and angles of attack occur. The effect of the current affecting the vehicle was analyzed by defining the sideslip and attack angles. The speed of the vehicle against the current coming from different directions and surge velocity was successfully controlled with the support vector machine. The all study was done in MATLAB / Simulink environment.

Keywords: Unmanned surface vehicle, Mathematical modelling, Speed control, Machine learning, Support vector machine.

\section{Giriş}

İnsansız su üstü araçları ticari, askeri ve bilimsel alanlarda arama/kurtarma çalışmalarında, çevre kontrolünde, liman güvenliğinde ve sualtı haritalandırmada gibi birçok uygulama alanı için önemlidir. İnsansız su üstü araçları kontrol sistemlerinin, sensör sistemlerinin, iletişim ve silah sistemlerinin gelişmesi ile birlikte bahsedilen görevleri yerine getirebilirler (Bertaska vd., 2015; Sarda vd., 2016). İnsansız su üstü araçlarının kontrolü aktif bir araştırma konusudur. Aguiar ve Pascoal, bilinmeyen bir akıntıda belirsiz hidrodinamik parametrelere sahip bir insansız su üstü aracını su yüzeyinde sabit tutabilmek için doğrusal olmayan bir uyarlamalı kontrolör tasarlamışlardır (Aguiar \& Pascoal, 2007). İnsansız su üstü araçları için kontrol teoremlerinin doğrulanması için büyük ölçekli deniz deneyleri yerine simülasyon ortamında veya küçük ölçekli deniz deneyleri ile gerçekleştirilir (Ashrafiuon vd., 2010). Su üstü ve insansız su üstü araçlarının kontrolüne dair ilgili literatür incelendiğinde; uyarlamalı kontrol, geri adım kontrolü (backstepping control), kademeli kontrol teorisi, kayan mod kontrol (sliding mode control), bulanık mantık kontrolü, yapay sinir ağı kontrolü, hibrit kontrol gibi çalışmalara sıkça rastlanabilir. M.Chen ve ark. su üstü araçlarının deniz üzerinde sabit kalabilmesi için değişken yap1 kontrolü ile birlikte uyarlanabilir kontrol önermişlerdir. Bu kontrol sistemini sinir ağları ile tasarlamışlardır (Chen vd., 2013). Z. Dong ve ark. yatay düzlemde bir USV'nin yörünge izleme problemini ele almak için durum geri besleme temelli bir geri adım kontrol algoritması tasarlamışlardır (Dong vd., 2015). İnsansız su üstü araçlarının kontrolü sağlanırken akıntı, rüzgar ve dalga önemli dış bozucu kaynaklarıdır (Sarda vd., 2016). 2016 yılında yine Z. Dong ve ark. insansız deniz araçlarının, farklı okyanus akıntı hızlarının ve yön açılarının varlığında geri adım yöntemine dayalı farklı yörünge izleme kontrol performanslarını incelemişlerdir (Dong vd., 2016). 2018 yılında M.Yong ve ark. insansız su üstü araçları (USV) için akıntı olan ortamlarda; yol uzunluğu, yol düzgünlüğü, ekonomik maliyet ve yol güvenliğini hedefleyerek yol planlama problemini incelemişlerdir. Yol planlamasını incelerken USV, akıntı etkisinin yanı sıra çarpışmadan kaçınma ve hareket sınırlarına da maruz bırakılmıştır (Ma vd., 2018). 2018 yilında L. Chengxing ve ark. hareket altındaki bir USV'nin hız ve yön açısı izleme kontrolü için kapalı döngü sisteminin kararlılığını analiz eden durum hatası port kontrollü bir kontrolör önermişlerdir (Lv vd., 2018). Daha önce litertürde olan kontrol tekniklerinden farklı olarak, bir insansız su üstü aracının hız kontrolü için destek vektör makinesi kullanılması bu çalışmanın katkısıdır.
Destek vektör makinesi (SVM) hem sinıflandırma hem de regresyon problemlerinde kullanılabilmektedir (Vapnik, 2000). Sinıflandırma problemlerinde daha sik kullanılan SVM, regresyon problemlerinde kullanılması Smola ve ark. tarafindan önerilmiştir (Smola \& Schölkopf, 2004).

Bu çalışmada insansız su üstü aracı için akıntı etkisi altında hız kontrolü yapılmıştır. USV'ye akıntı etki ettiğinde aracın istenen hızda kalabilmesi için uygun araç itici kuvvetlerinin tahmini SVM algoritması ile gerçekleştirilmiştir. SVM'nin eğitimi için gerekli olan veri seti, PID kontrolcü ile oluşturulmuştur. Burada SVM, aracın akıntı etkisi altında referans hızda sabit kalabilmesi için uygun itici girişlerini üretmektedir.

\section{Materyal ve Metot}

\subsection{Su Üstü Aracının Matematiksel Modeli}

Su üstü aracının doğrusal olmayan dinamik ve kinematik matematiksel modeli denklem 1 ve 2 de tanımlanmıştır (Fossen, 1999).

$$
\begin{gathered}
\mathrm{M}(\dot{\mathrm{v}})+\mathrm{C}(\mathrm{v}) \mathrm{v}+\mathrm{D}(\mathrm{v}) \mathrm{v}+\mathrm{g}(\eta)=\tau=\mathrm{u} \\
\dot{\eta}=\mathrm{J}(\eta) \mathrm{v}
\end{gathered}
$$

Burada, M, aracın kütle matrisi, C, merkezkaç kuvveti ve Coriolis kuvveti matrisi, D, sönümleme matrisi, g, yerçekimi ve suyun kaldırma kuvveti matrisi, v, aracın doğrusal ve açısal hız vektörü, $\eta$, aracın konum ve yönelim vektörü, J, koordinat çevirim matrisi, $\tau$, iticilerin üretmiş olduğu kuvvet ve momentlerden oluşan girdi vektörüdür. Aracın üç serbestlik derecesine sahip, x, $\mathrm{y}$ eksenindeki doğrusal hareket ve $\mathrm{z}$ eksenindeki dönme (sapma) hareketleri için araca etki eden kuvvet ve momentler ile hız ve konum bilgileri Tablo 1 de verilmiştir.

Denklem 1 ve 2 bu çalışmada kullanılacak olan, Şekil 1'de gösterilen su üstü aracının hareketi için 3 serbestlik derecesindeki tanımlanmıştır. Sistemin girdisi olan u matrisi iticilerin üretmiş oldukları moment ve kuvvetlerden oluşan sütün matrisidir. 
Tablo 1. Su üstü aracının hareket notasyonlarl

\begin{tabular}{|c|c|c|c|c|}
\hline $\begin{array}{c}\text { Serbestli } \\
\mathbf{k} \\
\text { Derecesi }\end{array}$ & $\begin{array}{c}\text { Konum } \\
\text { ve } \\
\text { Yönelimle } \\
\mathbf{r}\end{array}$ & $\begin{array}{c}\text { Kuvvet } \\
\text { ve } \\
\text { Momen } \\
\mathbf{t}\end{array}$ & $\begin{array}{c}\text { Doğrusa } \\
\mathbf{l} \text { ve } \\
\text { Açısal } \\
\text { Hzlar }\end{array}$ & $\begin{array}{c}\text { Pozisyo } \\
\text { n ve } \\
\text { Euler } \\
\text { Açıları }\end{array}$ \\
\hline 1 & $\begin{array}{c}x \\
\text { eksenindeki } \\
\text { hareket }\end{array}$ & $\mathrm{X}$ & $\mathrm{u}$ & $\mathrm{x}$ \\
\hline 2 & $\begin{array}{c}y \\
\text { eksenindeki } \\
\text { hareket }\end{array}$ & $\mathrm{Y}$ & $\mathrm{v}$ & $\mathrm{y}$ \\
\hline 3 & $\begin{array}{c}z \\
\text { eksenindeki } \\
\text { dönüş }\end{array}$ & $\mathrm{N}$ & $\mathrm{r}$ & $\psi$ \\
\hline
\end{tabular}

$\mathrm{Bu}$ çalışmada model olarak kullanılan su üstü aracında (WAM-USV14) 1 tane sağda 1 tane solda olmak üzere 2 adet itici yatay konumda yerleştirilmiştir. Yataydaki iticiler $\mathrm{x}$ ekseni yönündeki hareketi (surge) ve z ekseni etrafındaki dönmeyi (yaw) sağlarlar. WAM-USV14 aracın matematiksel modelinde, daha önce sistem tanılaması yapılarak elde edilen sönümleme parametreleri, katma kütle parametreleri kullanılmıștır (Klinger vd., 2017).

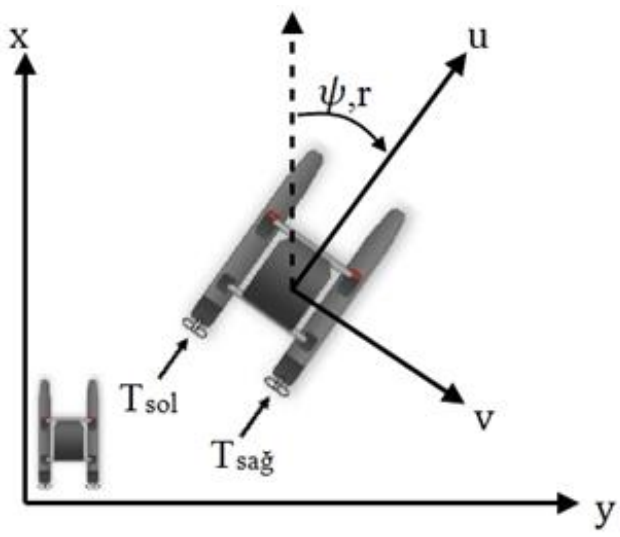

Şekil 1. Modellenen su üstü aracına ait iticiler ve yapabildiği hareketler (WAM-USV14)

Matematiksel modeldeki matrisler:

$$
\begin{gathered}
\mathrm{M}=\left[\begin{array}{ccc}
\mathrm{m}-\mathrm{X}_{\dot{\mathrm{u}}} & 0 & 0 \\
0 & \mathrm{~m}-\mathrm{Y}_{\dot{\mathrm{v}}} & 0 \\
0 & 0 & \mathrm{Iz}-\mathrm{N}_{\dot{\mathrm{r}}}
\end{array}\right] \\
\mathrm{C}=\left[\begin{array}{ccc}
0 & 0 & -\left(\mathrm{m}-\mathrm{Y}_{\dot{\mathrm{v}}}\right) \mathrm{v} \\
0 & 0 & \left(\mathrm{~m}-\mathrm{X}_{\dot{\mathrm{u}}}\right) \mathrm{u} \\
\left(\mathrm{m}-\mathrm{Y}_{\dot{\mathrm{v}}}\right) \mathrm{v} & -\left(\mathrm{m}-\mathrm{X}_{\dot{\mathrm{u}}}\right) \mathrm{u} & 0
\end{array}\right] \\
\mathrm{D}=-\left[\begin{array}{ccc}
\mathrm{X}_{\mathrm{u}} & 0 & 0 \\
0 & \mathrm{Y}_{\mathrm{v}} & 0 \\
0 & 0 & \mathrm{~N}_{\mathrm{r}}
\end{array}\right] \\
\mathrm{J}=\left[\begin{array}{ccc}
\cos (\psi) & -\sin (\psi) & 0 \\
\sin (\psi) & \cos (\psi) & 0 \\
0 & 0 & 1
\end{array}\right]
\end{gathered}
$$

Burada, m: aracin kütlesi, $\mathrm{X}_{\dot{\mathrm{u}}}, \mathrm{Y}_{\dot{\mathrm{v}}}, \mathrm{N}_{\dot{\mathrm{r}}}$ :aracın katma kütle parametreleri, $X_{u}, Y_{v}, N_{r}$ : aracın sönümleme parametreleri ve Iz: $\mathrm{z}$ eksenindeki atalet tensörüdür.
İticilerin üretmiş olduğu kuvvet ve momentden oluşan girdi vektörü Denklem 7'deki gibidir (Klinger vd., 2017). Burada B, iki itici arasındaki mesafedir.

$$
\tau=\left[\begin{array}{l}
\mathrm{T} 1 \\
\mathrm{~T} 2 \\
\mathrm{~T} 3
\end{array}\right]=\left[\begin{array}{c}
\text { Tsol }+ \text { Tsağ } \\
0 \\
(\text { Tsol-Tsağ }) *\left(\frac{\mathrm{B}}{2}\right)
\end{array}\right]
$$

\section{2. İnsansız Su Üstü Aracının Kontrolü}

İnsansız su üstü aracının ileri yön hızı, farklı hız ve farklı yönlerde araca etki eden akıntı olduğu durumlarda, makine öğrenmesi olan SVM algoritması ile kontrol edilmiştir. Şekil 2'de su üstü aracı kontrolünün blok şeması verilmiştir. SVM, aracın akıntı durumundaki hareketini kontrol etmek için iticilere gönderilmesi gereken bilgiyi tahmin etmektedir. SVM'nin eğitimini gerçekleştirmek için gerekli veri seti, aracın referans hızlarına karşı uygun itici bilgileri PID kontrolcüden elde edilerek oluşturulmuştur. Veri setini oluştururken PID kontolcülerin kazanç katsayıları, referans hız ile model cevabı hız arasındaki hatayı minimize edecek şekilde bulunmuştur.

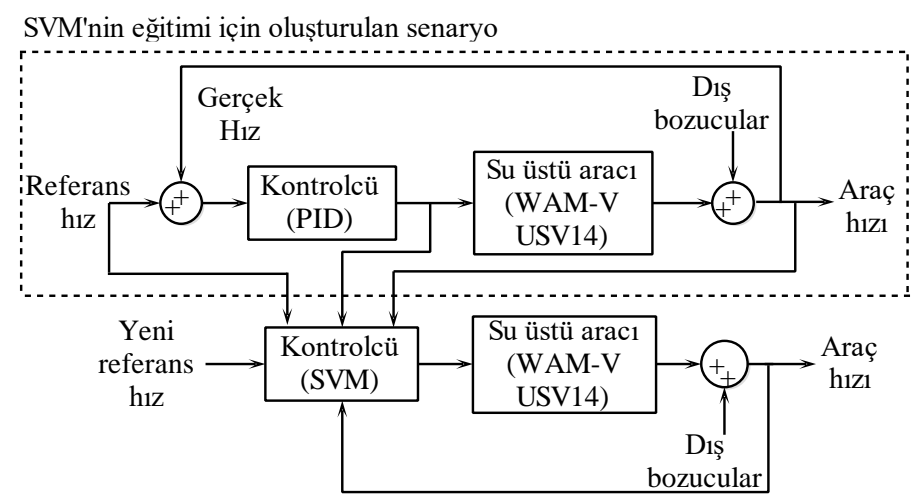

Şekil 2. SVM kontrolcü blok şemast

\subsubsection{Su Üstü Aracı Hareketine Akıntı Etkisi}

$\mathrm{Su}$ üstü aracına etki eden akıntı sebebi ile aracın yanal hareketinde etkili olan yana kayma (sideslip), $\beta$, açısı ve sapma açısı $(\psi)$ Şekil 3 'te, su üstü aracının dikeydeki hareketinde etkili olduğu hücum açısı, $\alpha$, Şekil 4'te gösterilmiştir. Vücut (body) yapı eksenleri ve dünya yapı eksenleri sırasıyla $\mathrm{x}^{\mathrm{b}}, \mathrm{y}^{\mathrm{b}}, \mathrm{z}^{\mathrm{b}}$ ve $\mathrm{x}^{\mathrm{n}}$, $\mathrm{y}^{\mathrm{n}}, \mathrm{z}^{\mathrm{n}}$ olarak gösterilmiştir (Fossen, 1999).

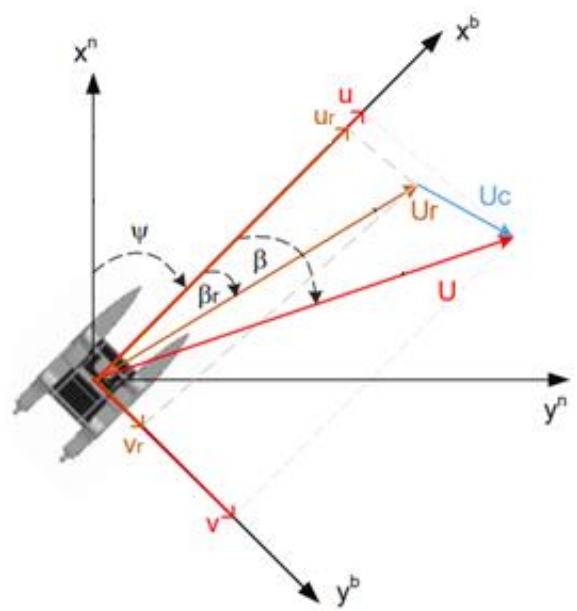

Şekil 3. Sapma açısı ve yana kayma açısı 


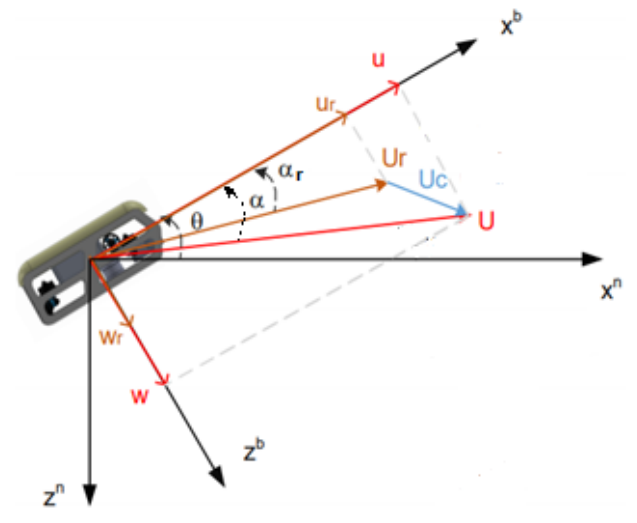

(b)

\section{Şekil 4. Hücum açısı}

Hücum açısı ve yana kayma açısı Denklem 8'deki gibi tanımlanır.

$$
\alpha=\tan ^{-1} \frac{\mathrm{w}}{\mathrm{u}}, \beta=\sin ^{-1} \frac{\mathrm{v}}{\mathrm{U}}
$$

Burada $\mathrm{u}, \mathrm{v}, \mathrm{w}$ aracın $\mathrm{x}, \mathrm{y}$ ve $\mathrm{z}$ eksenlerindeki doğrusal hızlarıdır. U ile gösterilen aracın hız vektörüdür ve yatay hareket için $U=\sqrt{\mathrm{u}^{2}+\mathrm{v}^{2}}$ olarak tanımlanır. Akıntı varlığında bağıl hücum açısı $\left(\alpha_{\mathrm{r}}\right)$ ve bağıl yana kayma açısı $\left(\beta_{\mathrm{r}}\right)$ Denklem 9'daki gibi tanımlanır:

$$
\alpha_{\mathrm{r}}=\tan ^{-1} \frac{\mathrm{w}_{\mathrm{r}}}{\mathrm{u}_{\mathrm{r}}}, \beta_{\mathrm{r}}=\sin ^{-1} \frac{\mathrm{v}_{\mathrm{r}}}{\mathrm{U}_{\mathrm{r}}}
$$

Burada, $\mathrm{u}_{\mathrm{r}}, \mathrm{v}_{\mathrm{r}}, \mathrm{w}_{\mathrm{r}}$ sirasiyla aracin $\mathrm{x}, \mathrm{y}$ ve $\mathrm{z}$ eksenlerindeki bağıl doğrusal hızlardır. Akıntı hızını $x, y$ ve $z$ eksenlerinde sirasıyla $u_{c}, v_{c}, w_{c}\left(\right.$ akıntı hızı, $U_{c}=\sqrt{u_{c}^{2}+v_{c}^{2}+w_{c}^{2}}$ ) ise, aracın bağıl doğrusal hızları, $u_{r}=u-u_{c}, v_{r}=v-v_{c}$, $\mathrm{w}_{\mathrm{r}}=\mathrm{w}-\mathrm{w}_{\mathrm{c}}$ olarak tanımlanır. $\mathrm{U}_{\mathrm{r}}$ ile gösterilen aracın bağıl hızıdır ve 3D hareket için $U_{r}=\sqrt{u_{r}^{2}+v_{r}^{2}+w_{r}^{2}}$.

$\mathrm{Bu}$ çalışmada kullanılacak su üstü aracı için, akıntı yok ise hücum açısı ve yana kayma açısı sıfırdır. Bu açıların etkisi ancak akıntı varlığında incelenebilir. Akıntının var olduğu ortamda, aracın hızı için bağıl hız bağıntısı geçerlidir.

\subsection{Destek Vektör Makinesi ile Kontrol}

Destek vektör makinesi, istatistiksel öğrenme teorisine dayanıp Vapnik tarafından geliştirilmiştir (Vapnik, 2000). SVM, doğrusal ve doğrusal olmayan problemlerde hem sinıflandırma hem de regresyon işlemlerinde kullanılan bir makine öğrenme yöntemidir (Smola \& Schölkopf, 2004). SVM' de amaç verilen giriş değişkenleri ile çıkış değiş̧kenleri arasındaki bağlantıyı kurmaktır. $\mathrm{x}_{\mathrm{i}}$ giriş değiş̧kenleri, $\mathrm{y}_{\mathrm{i}}$ ise bu girişlere denk gelen çıkış değişkenleri olan $\mathrm{D}=\{(\mathrm{x} 1, \mathrm{y} 1),(\mathrm{x} 2, \mathrm{y} 2), \ldots,(\mathrm{xi}, \mathrm{yi})\}$ den oluşan bir veri seti olsun. SVM algoritması xi'ler ile yi'lerin ilişkisini en doğru şekilde oluşturulacak fonksiyonu bulmaktadır. SVM bu fonksiyonu bulur iken aşağıda verilen $\mathrm{J}$ maliyet fonksiyonunu minimize eden optimizasyon problemini çözmektedir.

Maliyet fonksiyonu (J):

$$
\mathrm{J}=\frac{1}{2}\|\mathrm{w}\|^{2}+\mathrm{K} * \sum_{\mathrm{i}=1}^{\mathrm{m}}\left(\xi_{\mathrm{i}}+\xi_{\mathrm{i}}^{*}\right)
$$

$$
\begin{gathered}
\mathrm{y}_{\mathrm{i}}-\left(\mathrm{w}^{*} \mathrm{x}_{\mathrm{i}}\right)-\mathrm{b} \leq \varepsilon+\xi_{\mathrm{i}} \\
\left(\mathrm{w}^{*} \mathrm{x}_{\mathrm{i}}\right)+\mathrm{b}-\mathrm{y}_{\mathrm{i}} \leq \varepsilon+\xi_{\mathrm{i}}^{*} \\
\xi_{\mathrm{i}}, \xi_{\mathrm{i}}^{*} \geq 0, \quad \mathrm{i}=1, \ldots, \mathrm{m}
\end{gathered}
$$

Burada, K parametresi sıfırdan büyük bir sayıdır ve eğitime dahil edilecek olan verileri belirlemede kullanılmaktadır. Veri setine göre değişiklik göstermektedir. Bu yüzden deneme ile bulunmaktadır. $\xi_{i}$ ve $\xi_{i}^{*}$ ise eğitime dahil edilmeyen verilerin eğitime dahil edilen verilere olan uzaklıkları ifade etmektedir. $\varepsilon$, sıfırdan büyük bir sayı olup kullanıcı tarafindan belirlenmektedir. b, oluşturulan fonksiyonda algoritmanın belirlediği bir sabit sayıdır. w ise verilen xi giriş değişkenleri ile çarpılacak sayı olup algoritma tarafindan belirlenmektedir.

\section{Simülasyon Sonuçları}

Yapılan bu çalışmada, insansız su üstü aracına etki eden akıntı SVM algoritması ile incelendi. İnsansız su üstü aracına etki eden akıntı ile birlikte aracın istenilen hızda kalması amaçlandı. İnsansız su üstü aracının istenilen hızda kalması için iticilerine verilecek kuvvetin tahmini SVM algoritması ile yapıldı. İlk olarak SVM algoritmasının eğitimi için veri seti oluşturuldu. Veri seti için PID kontrolcüsü kullanıldı ve gelen akıntıya karşılık itici kuvvetleri PID kontrolcü ile belirlendi. Oluşturulan veri seti ile birlikte SVM algoritmasının eğitimi gerçekleştirildi. İnsansız su üstü aracına etki eden akıntı altı farklı yönde incelendi. İncelenen akıntı yönleri Şekil 4'te gösterilmektedir. Şekil 5 'te gösterilen altı farklı akıntı yönünde insansız su üstü aracına farklı değerlerde akıntı hızları uygulanmıştır. Böylece aracın istenilen hızda kalabilmesi için gerekli itici kuvvetleri eğitimi gerçekleştirilen SVM algoritması tarafından tahmin edilmiştir.

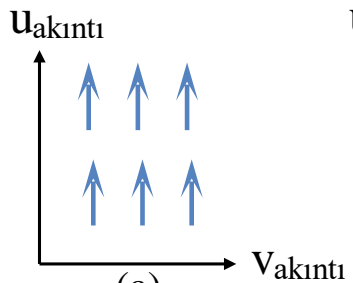

(a)

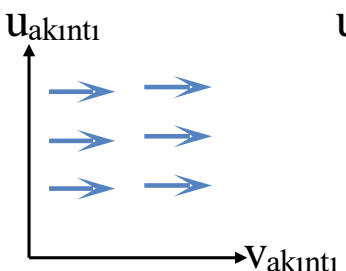

(c)

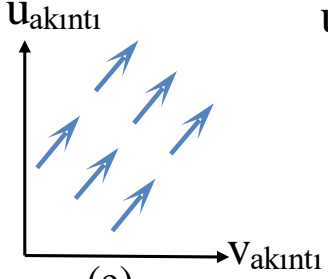

(e)

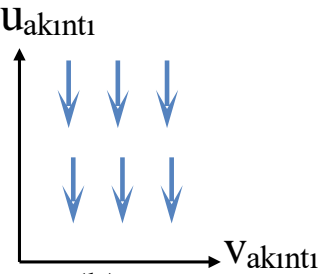

(b)

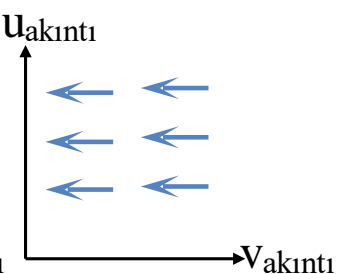

(d)

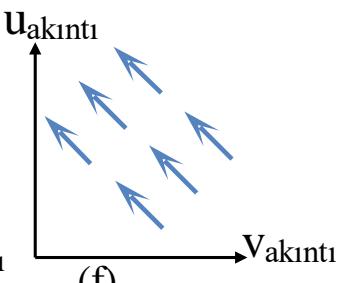

(f)

Şekil 5. Araca etki eden akıntı yönleri

Kisitlar: 

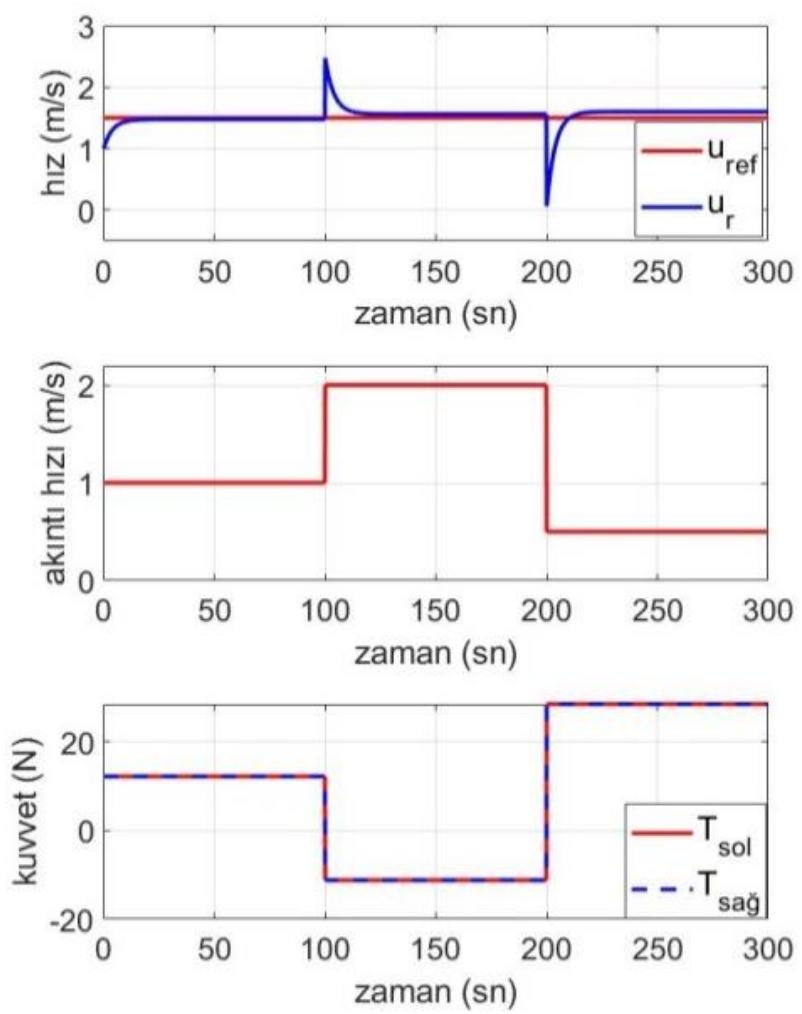

Şekil 6. Araca uygulanan ileri-yön referans hiz ve gerçek ileri-yön hızı, araca etki eden akıntı hızı ve akıntı varlı̆̆ında aracın referans hızı takip edebilmesi için gerekli sağ ve sol itici kuvvetleri (SVM ile elde edilen)
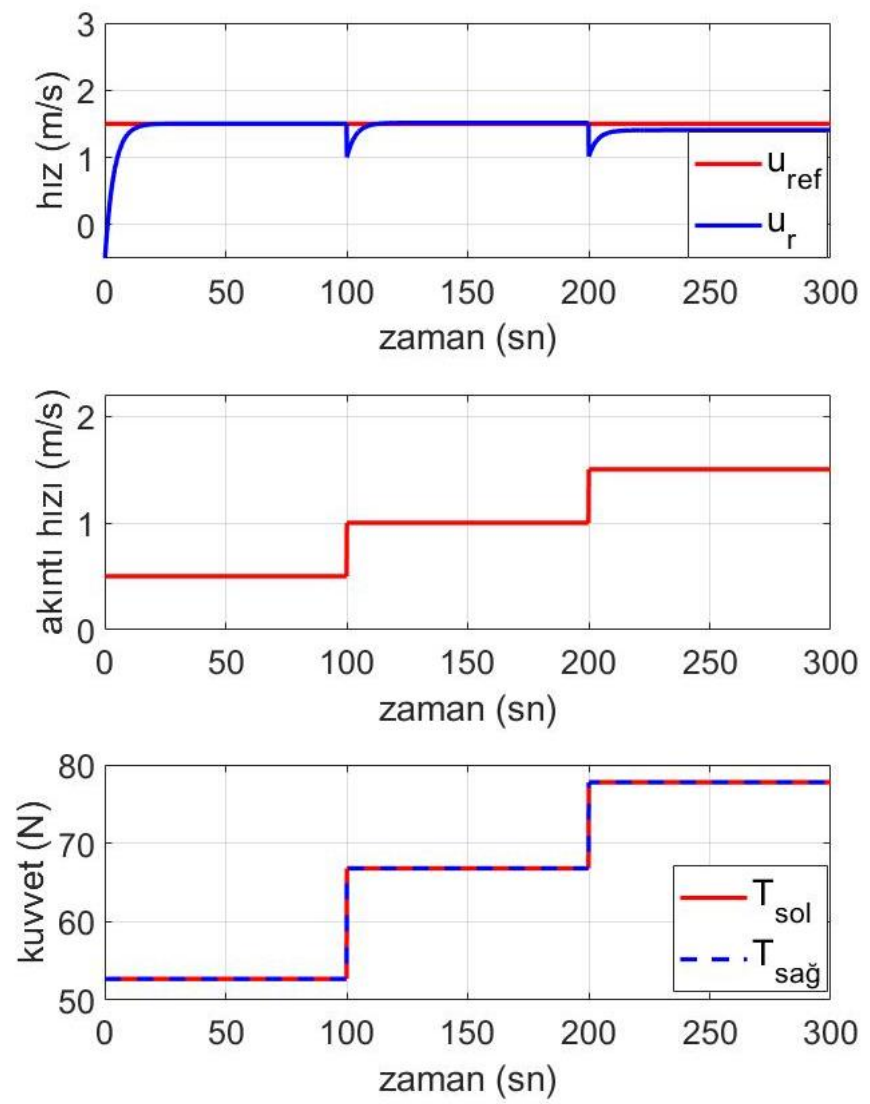

Şekil 7. Araca uygulanan ileri-yön referans hiz ve gerçek ileri-yön hızı, araca etki eden akıntı hızı ve akıntı varlığında aracın referans hızı takip edebilmesi için gerekli sağ ve sol itici kuvvetleri (SVM ile elde edilen)
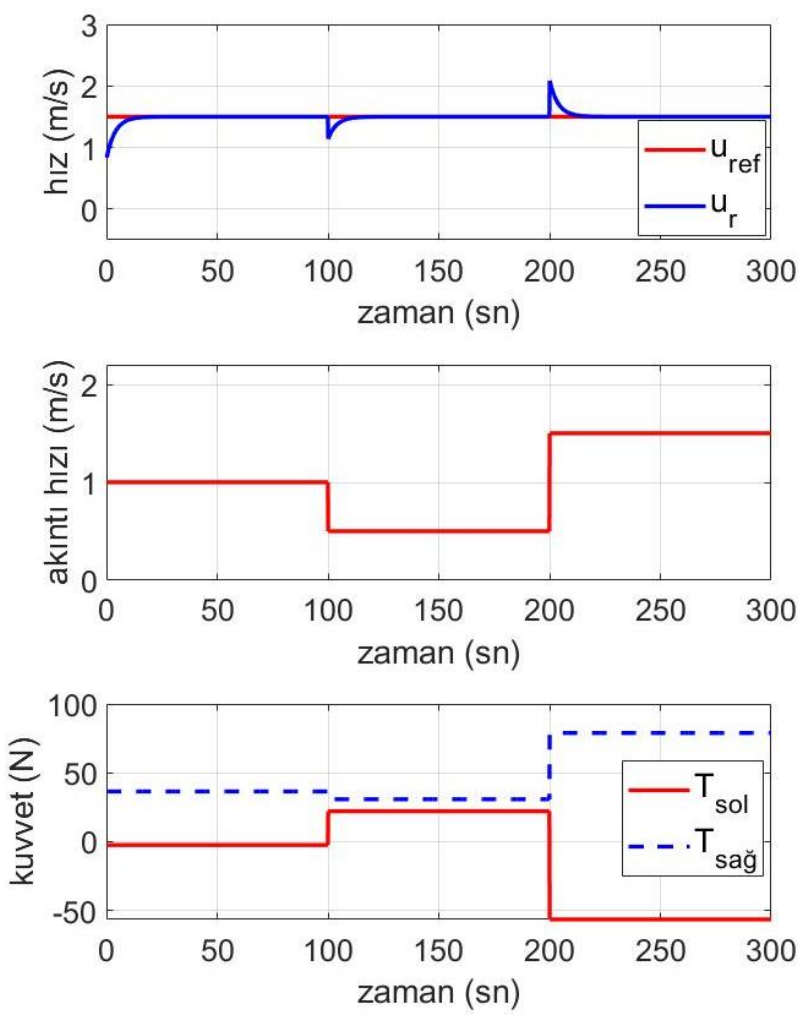

Şekil 8. Araca uygulanan ileri-yön referans hız ve gerçek ileri-yön hızı, araca etki eden akıntı hızı ve akıntı varlı̆̆ında aracın referans hızı takip edebilmesi için gerekli sağ ve sol itici kuvvetleri (SVM ile elde edilen)

Şekil 6'da araca etki eden akıntının yönü Şekil 5 (a)'da gösterildiği gibidir ve araca etki eden akıntı yönü ile araç yönü aynı eksen üzerindedir. Akıntı hızı sırasıyla $1 \mathrm{~m} / \mathrm{s}, 2 \mathrm{~m} / \mathrm{s}$ ve 0.5 $\mathrm{m} / \mathrm{s}$ olarak verilmiştir. Aracın referans hızı $1.5 \mathrm{~m} / \mathrm{s}$ olarak belirlenmiştir. Böylece araç ileri yön hareketini yaparak referans hızı takip edebilmesi için uygulanması gereken uygun itici kuvvetleri SVM tarafından bulunmuştur. Şekil 7'de araca etki eden akıntının yönü Şekil 5 (b)'de gösterildiği gibidir ve araca etki eden akıntı yönü ile araç yönü birbirine ters yöndedir. Akıntı hızı sırasıyla $0.5 \mathrm{~m} / \mathrm{s}, 1 \mathrm{~m} / \mathrm{s}$ ve $1.5 \mathrm{~m} / \mathrm{s}$ olarak verilmiştir. Böylece araç ileri yön hareketini yapabilmesi için sağ ve sol iticilere uygulanacak uygun itici kuvvetleri SVM tarafindan bulunmuştur. Şekil 8'de araca etki eden akıntının yönü Şekil 5 (c)'de gösterildiği gibidir ve araca etki eden akıntı yönü araç ileri yön hareketini yaparken araca soldan etki edecek şekildedir. Şekil 9'da araca etki eden akıntının yönü Şekil 5 (d)'de gösterildiği gibidir ve araca etki eden akıntı yönü araç ileri yön hareketini yaparken araca sağdan etki edecek şekildedir. Akıntı hızı sırasıyla $1.5 \mathrm{~m} / \mathrm{s}, 1 \mathrm{~m} / \mathrm{s}$ ve $0.5 \mathrm{~m} / \mathrm{s}$ olarak verilmiştir. Şekil 10'da araca etki eden akıntının yönü Şekil 5 (e)'de gösterildiği gibidir ve araca etki eden akıntı yönü araç ileri yön hareketini yaparken araca sol arka çaprazdan etki edecek şekildedir. Akıntı hızı sırasıyla $0.5 \mathrm{~m} / \mathrm{s}, 1$ $\mathrm{m} / \mathrm{s}$ ve $1.5 \mathrm{~m} / \mathrm{s}$ olarak verilmiştir. Şekil 11'de araca etki eden akıntının yönü Şekil 5 (f)'de gösterildiği gibidir ve araca etki eden akıntı yönü araç ileri yön hareketini yaparken araca sağ arka çaprazdan etki edecek şekildedir. Akıntı hızı sırasıyla $0.5 \mathrm{~m} / \mathrm{s}, 1$ $\mathrm{m} / \mathrm{s}$ ve $1.5 \mathrm{~m} / \mathrm{s}$ olarak verilmiştir. Araç ileri yön hareketini yaparak referans hızı takip edebilmesi için sağ ve sol iticilere uygulanması gereken itici kuvvetleri SVM tarafindan belirlenmiştir. 

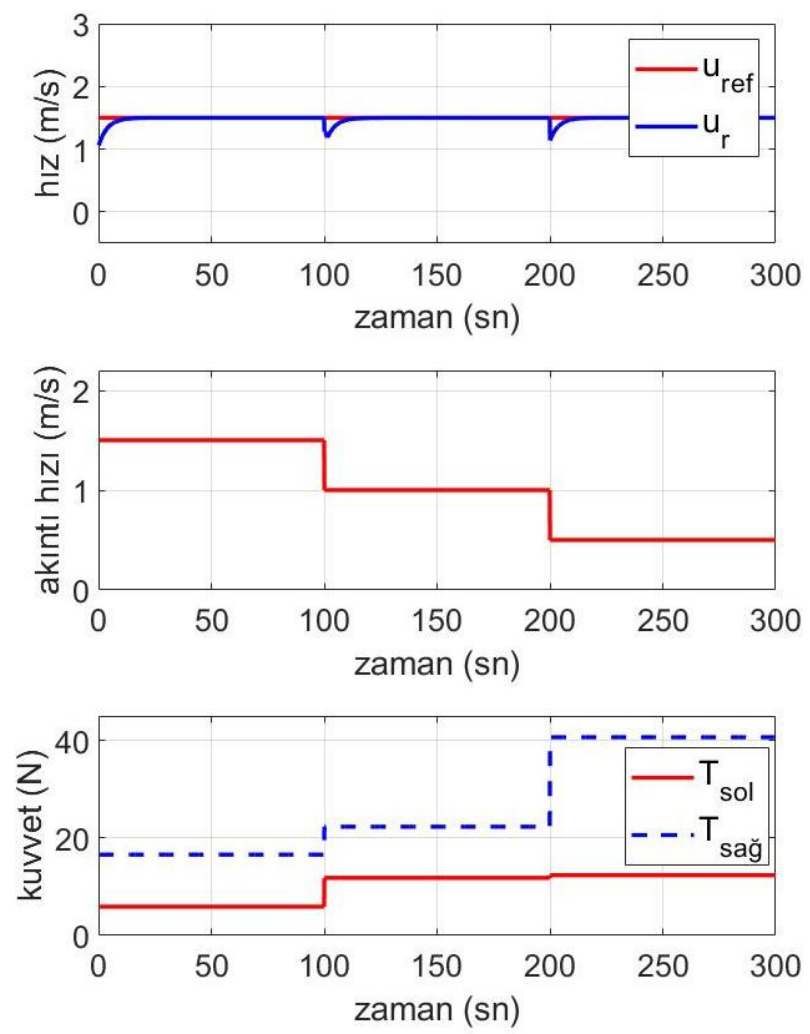

Şekil 9. Araca uygulanan ileri-yön referans hiz ve gerçek ileri-yön hızı, araca etki eden akıntı hızı ve akıntı varlığında aracın referans hızı takip edebilmesi için gerekli săg ve sol itici kuvvetleri (SVM ile elde edilen)
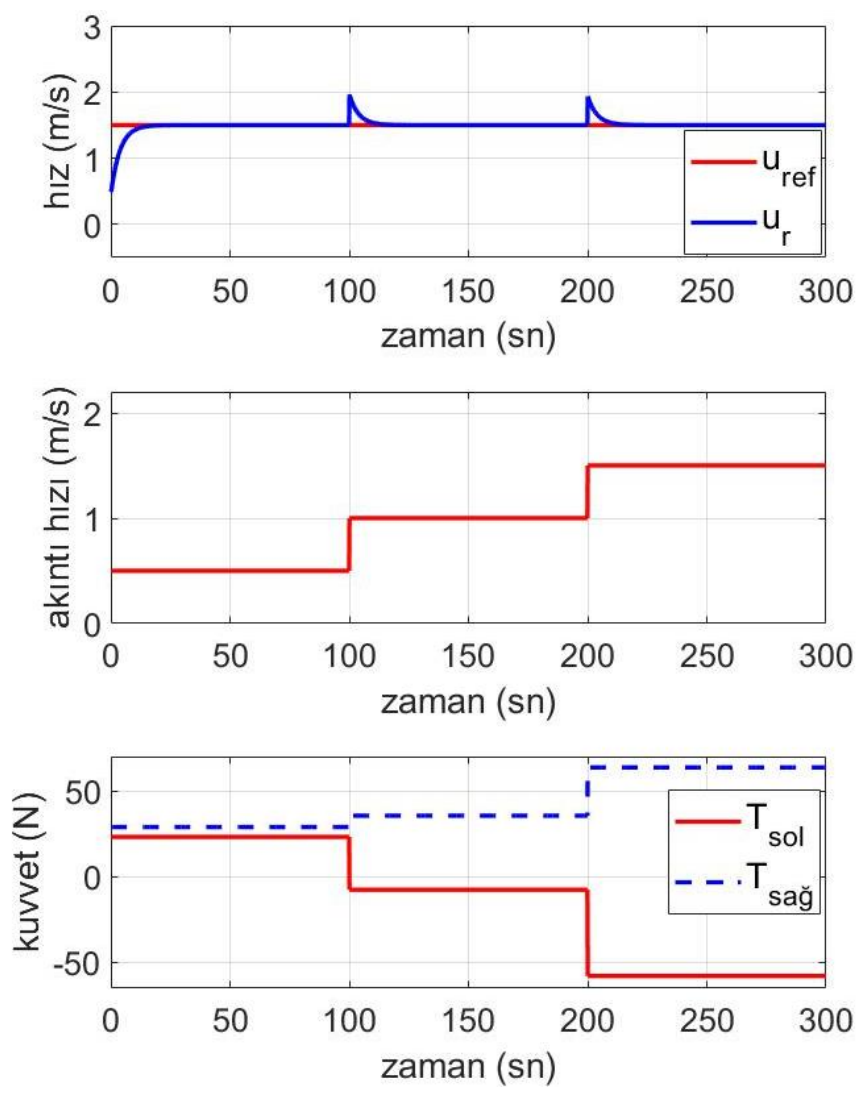

Şekil 10. Araca uygulanan ileri-yön referans hiz ve gerçek ileriyön hızı, araca etki eden akıntı hızı ve akıntı varlığında aracın referans hızı takip edebilmesi için gerekli sağ ve sol itici kuvvetleri (SVM ile elde edilen)
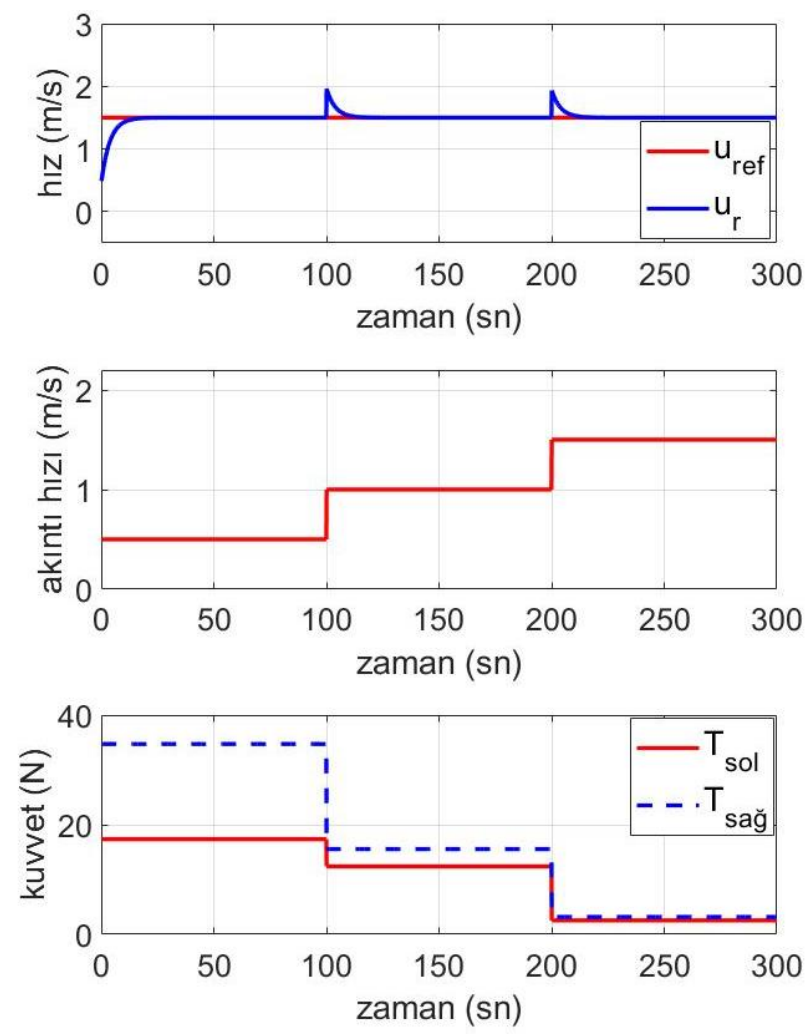

Şekil 11. Araca uygulanan ileri-yön referans hiz ve gerçek ileriyön hızı, araca etki eden akıntı hızı ve akıntı varlığında aracın referans hız takip edebilmesi için gerekli sağ ve sol itici kuvvetleri (SVM ile elde edilen)

Tablo 2'de insansız su üstü aracına farklı değerlerde ve yönlerde etki eden akıntı hızına karşılık gelen araç itici değerleri ve yana kayma açıları sunulmuştur. Yana kayma açıları Denklem 9'dan hesaplanmıştır. Bu çalışmada dikkate alınan insansız su üstü aracı, akıntının olmadığı ortam şartlarında ileri yön hareketi için $1.5 \mathrm{~m} / \mathrm{s}$ hıza sağ ve sol iticilere $40 \mathrm{~N}$ uygulandığında ulaşmaktadır.

Tablo 2. Akıntı hızı ve yönüne karşılık gelen itici kuvvetleri

\begin{tabular}{|c|c|c|c|c|}
\hline $\begin{array}{l}\text { Akıntı } \\
\text { Yönü }\end{array}$ & $\begin{array}{c}\text { Akıntı } \\
\text { Hızı } \\
(\mathbf{m} / \mathbf{s})\end{array}$ & $\begin{array}{c}\text { Sol Ítici } \\
\left(\mathbf{T}_{\text {sol }}\right) \\
(\mathbf{N})\end{array}$ & $\begin{array}{c}\text { Sağ İtici } \\
\left(\mathbf{T}_{\text {sağ }}\right) \\
(\mathbf{N})\end{array}$ & $\begin{array}{c}\text { Yana } \\
\text { Kayma } \\
\text { Açısı } \\
\text { (derece) }\end{array}$ \\
\hline Şekil 5 (a) & 1 & 12.21 & 12.21 & 0 \\
\hline Şekil 5 (a) & 2 & -11.16 & -11.16 & 0 \\
\hline Şekil 5 (a) & 0.5 & 28.48 & 28.48 & 0 \\
\hline Şekil 5 (b) & 0.5 & 52.7 & 52.7 & 180 \\
\hline Şekil 5 (b) & 1 & 66.8 & 66.8 & 180 \\
\hline Şekil 5 (b) & 1.5 & 77.77 & 77.77 & 180 \\
\hline Şekil 5 (c) & 1 & -2.43 & 36.52 & 33.367 \\
\hline Şekil 5 (c) & 0.5 & 22.17 & 30.8 & 18.4487 \\
\hline
\end{tabular}




\begin{tabular}{|l|c|c|c|c|}
\hline Şekil 5 $(c)$ & 1.5 & -56.48 & 78.9 & 45 \\
\hline Şekil 5 $(d)$ & 1.5 & 5.89 & 16.57 & -45 \\
\hline Şekil 5 $(d)$ & 1 & 11.8 & 22.31 & -33.367 \\
\hline Şekil 5 $(d)$ & 0.5 & 12.34 & 40.62 & -18.4487 \\
\hline Sekil 5 $(e)$ & 0.5 & 23.19 & 28.89 & 10.8 \\
\hline Şekil 5 $(e)$ & 1 & -7.58 & 35.52 & 17.45 \\
\hline Şekil 5 $(e)$ & 1.5 & -57.88 & 63.58 & 22.33 \\
\hline Şekil 5 $(f)$ & 0.5 & 11.36 & 34.72 & -10.8 \\
\hline Şekil 5 $(f)$ & 1 & 12.14 & 15.55 & -17.45 \\
\hline Şekil 5 $(f)$ & 1.5 & 2.53 & 3.17 & -22.33 \\
\hline
\end{tabular}

Dong, Z., Wan, L., Li, Y., Liu, T., \& Zhang, G. (2015). Trajectory tracking control of underactuated USV based on modified backstepping approach. International Journal of Naval Architecture and Ocean Engineering, 7(5), 817-832. https://doi.org/10.1515/ijnaoe-2015-0058

Dong, Z., Wan, L., Liu, T., \& Zeng, J. (2016). Horizontal-Plane Trajectory-Tracking Control of an Underactuated Unmanned Marine Vehicle in the Presence of Ocean Currents. International Journal of Advanced Robotic Systems, 13(3), 83. https://doi.org/10.5772/63634

Fossen, T. I., Guidance and Control of Ocean Vehicles. Wiley, 1999.

Klinger, W. B., Bertaska, I. R., von Ellenrieder, K. D., \& Dhanak, M. R. (2017). Control of an Unmanned Surface Vehicle With Uncertain Displacement and Drag. IEEE Journal of Oceanic Engineering, 42(2), 458-476. https://doi.org/10.1109/JOE.2016.2571158

Lv, C., Yu, H., Hua, Z., Li, L., \& Chi, J. (2018). Speed and Heading Control of an Unmanned Surface Vehicle Based on State Error PCH Principle. Mathematical Problems in Engineering, 2018, https://doi.org/10.1155/2018/7371829

\section{Sonuç ve Yorum}

Bir insansız su üstü aracının doğrusal olmayan matematiksel modeli elde edilmiştir. Okyanus akıntısı gibi dış bozucularda su üstü aracı referans hızı takip edebilmesi için, sağ ve sol iticilerine uygulanması gereken kuvvet, makine öğrenmesi olan SVM ile elde edilmiştir. SVM'nin eğitiminde kullanılan veriseti, PID kontrol tekniği ile dış bozucu olmadan farklı referans hızlarda araca üretilen girdi bilgilerinden oluşturulmuştur. Araca farklı yön ve farklı hızlarda dış bozucu etki ettiğinde SVM' nin ürettiğgi kuvvet bilgisini iticilere uyguladığımızda aracın hız kontrolünün başarıyla yapıldığı gözlemlenmiş̦tir. Literatürde kullanılan kontrol tekniklerinden farklı olarak makine öğrenmesinin su üstü aracının kontrolünde kullanılması çalışmanın büyük katkısıdır. $\mathrm{Bu}$ çalışmanın devamı olarak deniz ya da havuzdan alınan deneysel veriler kullanılarak SVM'nin performansı analiz edilecektir. Tüm çalışma MATLAB/Simulink ortamında hazırlanmıştır.

\section{Kaynakça}

Aguiar, A. P., \& Pascoal, A. M. (2007). Dynamic positioning and way-point tracking of underactuated AUVs in the presence of ocean currents. International Journal of Control, 80(7), 10921108. https://doi.org/10.1080/00207170701268882

Ashrafiuon, H., Muske, K. R., \& McNinch, L. C. (2010). Review of nonlinear tracking and setpoint control approaches for autonomous underactuated marine vehicles. Proceedings of the 2010 American Control Conference, 5203-5211. https://doi.org/10.1109/ACC.2010.5530450

Bertaska, I. R., Shah, B., von Ellenrieder, K., Švec, P., Klinger, W., Sinisterra, A. J., Dhanak, M., \& Gupta, S. K. (2015). Experimental evaluation of automatically-generated behaviors for USV operations. Ocean Engineering, 106, 496514. https://doi.org/10.1016/j.oceaneng.2015.07.002

Chen, M., Ge, S. S., How, B. V. E., \& Choo, Y. S. (2013). Robust Adaptive Position Mooring Control for Marine Vessels. IEEE Transactions on Control Systems Technology, 21(2), 395-409. https://doi.org/10.1109/TCST.2012.2183676 